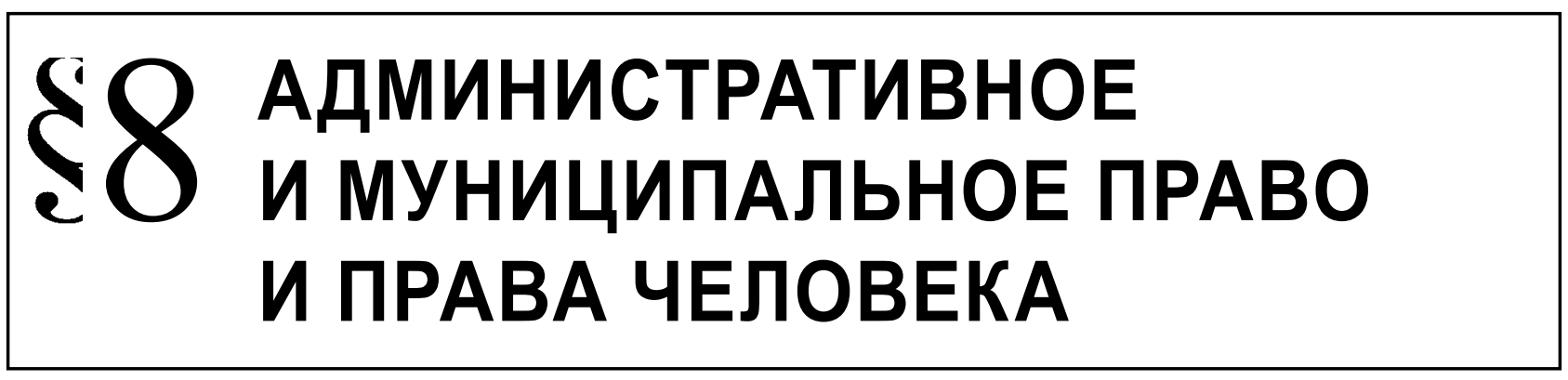

Шагара Г.В.

\title{
ПРОБЛЕМЫ ОСУЩЕСТВЛЕНИЯ КОНСТИТУЦИОННОГО ПРАВА ГРАЖДАН НА ТАЙНУ ТЕЛЕФОННЫХ ПЕРЕГОВОРОВ И ИНЫХ СООБЩЕНИЙ
}

\begin{abstract}
Аннотация: в статье излагаются особенности реализации конституционного права на тайну телефонных переговоров и иных сообщений на современном этапе развития общества. В статье отмечается, что самостоятельность и ценность конституционного права каждого на тайну телефонных переговоров как гарантии общих основных прав имеет особую значимость. В статье отмечается этот подход законодателя, возведшего названную гарантию в конституционный ранг, которая, наряду с другими, играет важную роль в правовом статусе человека и гражданина Российской Федерации, взаимоотношениях гражданина и государства на современном этапе развития российского общества. В статье также обращается внимание на одно обстоятельство, имеющее существенное значение в реализации права на тайну телефонных переговоров. Методологическую основу статьи составили современные достижения теории познания. В процессе исследования применялись общефилософский, теоретический, эмпирический методы (диалектика, системный метод, анализ, синтез, аналогия, дедукция, наблюдение, моделирование), традиционно правовые методы (формально-логический), методы, используемые в конкретно-социологических исследованиях (статистические, экспертные оценки и др.). Так, международно-правовые акты, равно как и Конституция Российской Федерации, не рассматривают право на тайну телефонных переговоров как право абсолютное. В статье отмечается, что это право согласно международно-правовым документам может быть ограничено при законодательно определенных условиях. Однако такие условия в указанных актах не определяются. Они получили более четкую регламентацию в праве Европейского сообщества, закрепляющего право на уважение корреспонденции. Из анализа $\mathrm{cm}$. 23 Конституции Российской Федерации следует, что право на тайну телефонных переговоров является составляющей неприкосновенности частной жизни, личной и семейной тайны, защиты своей чести и доброго имени. Посягательство на тайну телефонных переговоров одновременно является посягательством на неприкосновенность частной жизни, личной и семейной тайны, защиту чести и доброго имени. Обеспечение соблюдения этого права выступает гарантией неприкосновенности частной жизни, личной и семейной тайны, защиты чести и доброго имени.
\end{abstract}

Ключевые слова: тайна, телефон, информация, сведения, личность, человек, защита, Конституция, секрет, охрана.

И 3 анализа ст. 23 Конституции Российской Федерации следует, что право на тайну телефонных переговоров является составляющей неприкосновенности частной жизни, личной и семейной тайны, защиты своей чести и доброго имени. Посягательство на тайну телефонных переговоров одновременно является посягательством на неприкосновенность частной жизни, личной и семейной тайны, защиту чести и доброго имени. Обеспечение соблюдения этого права выступает гарантией неприкосновенности частной жизни, личной и семейной тайны, защиты чести и доброго имени.

Как представляется, такая позиция российского законодателя заимствована из международно-правовых актов. В частности, в ст. 12 Всеобщей 
декларации прав человека ${ }^{1}$ говорится: «Никто не может подвергаться произвольному вмешательству в его личную и семейную жизнь, произвольным посягательствам на неприкосновенность его жилища, тайну его корреспонденции или на его честь и репутацию». Конвенция о защите прав человека и основных свобод 1950 г., закрепляя упомянутые права, ограничивается краткой формулировкой, в которой сказано: «Каждый имеет право на уважение его личной и семейной жизни, его жилища и его корреспонденции» (ч.1 ст. 8). Подобное положение содержится и в ст.17 Международного пакта о гражданских и политических правах ${ }^{3}$, где сказано, что «никто не может подвергаться произвольному или незаконному вмешательству в его личную и семейную жизнь, произвольным или незаконным посягательствам на неприкосновенность его жилища или тайну его корреспонденции или незаконным посягательствам на его честь и репутацию».

Исходя из международно-правового подхода, конституционного статуса человека и гражданина $^{4}$, право каждого на тайну телефонных переговоров закрепляется в Конституции Российской Федерации, во-первых, как одно из самостоятельных основных прав (ч.2 ст. 23); во-вторых, как гарантия права на неприкосновенность частной жизни, личную и семейную тайну (ч.1 ст.23) и, в-третьих, как одна из основ правового статуса личности в Российской Федерации (ст. 64).

Право на тайну телефонных переговоров выступает в качестве общего основного права 5 , гаран-

\footnotetext{
Всеобщая декларация прав человека: принята и провозглашена резолюцией 217 (III) Генеральной Ассамблеи ООН от 10 декабря 1948 г. // Международные акты о правах человека: сб. документов. - М., 1999. - С. 39-43.

2 Конвенция о защите прав человека и основных свобод. Рим, 4 ноября 1950 г. // Сборник документов Совета Европы в области защиты прав человека и борьбы с преступностью. М., 1998. - C.34-49.

3 Международный пакт о гражданских и политических правах: Принят и открыт для подписания, ратификации и присоединения резолюцией 2200 А (XXI) Генеральной Ассамблеи от 16 декабря 1966 г. // Международные акты о правах человека: сб. документов. - М., 1999. - С. 53-68.

4 О конституционно-правовом статусе человека и гражданина более подробно см.: Витрук, Н.В. Общая теория правового положения личности / Н.В. Витрук. - М., 2008; Козлова, Е.И. Конституционное право России / Е.И. Козлова, О.Е. Кутафин. - М. 2012. - С. $199-227$; Озиев, Т.Т. Конституционное право / Т.Т. Озиев. - М., 2009. - С. 52-71.

5 Баглай, М.В. Конституционное право Российской Федерации / М.В. Баглай. - М., 1997. - С.182.
}

тированного дополнительными конституционными нормами (ч.1 ст. 24 - запрет на сбор, хранение, использование и распространение информации о частной жизни лица без его согласия; ч.1 ст. $25-$ неприкосновенность жилища; ч. 1 ст. 26 - запрет на принуждение к определению и указанию своей национальной принадлежности и др.).

Дополнительными гарантиями выступают и положения отдельных федеральных законов Российской Федерации, которые регулируют рассматриваемые правоотношения. Так, Федеральный закон «0 почтовой связи» ${ }^{6}$ в качестве принципа деятельности в области почтовой связи провозглашает «обеспечение права каждого на тайну связи» (ст. 5), в качестве которой называет «тайну переписки, почтовых, телеграфных и иных сообщений, входящих в сферу деятельности операторов почтовой связи, не подлежащую разглашению без согласия пользователя услуг почтовой связи» (ст.2). Часть 1 ст. 63 Федерального закона «О связи» ${ }^{7}$ гласит: «На территории Российской Федерации гарантируется тайна переписки, телефонных переговоров, почтовых отправлений, телеграфных и иных сообщений, передаваемых по сетям электросвязи ${ }^{8}$ и сетям почтовой связи ${ }^{9}$ » (ч.1 ст. 63). Отметим, что одним из принципов функционирования Государственной автоматизированной информационной системы «ЭРА-ГЛОНАСС» (глобальная навигационная спутниковая система) провозглашается «соблюдение при автоматизированной обработке информации конституционных прав граждан на неприкосновенность частной жизни» (п. 3 ст. 3 Федерального закона Российской Федерации от 28 декабря 2013 г. № 395-Ф3 «О Государственной автоматизированной информационной системе «ЭРА-ГЛОНАСС ${ }^{10}$.

6 О почтовой связи: Федеральный закон Российской Федерации от 17 июля 1999 года № 176-Ф3 ( в послед. ред.).

О связи: Федеральный закон Российской Федерации от 7 июля 2003 года № 126-Ф3 (с послед. изм.).

8 «Электросвязь - любые излучения, передача или прием знаков, сигналов, голосовой информации, письменного текста, изображений, звуков или сообщений любого рода по радиосистеме, проводной, оптической и другим электромагнитным системам» (п.35 ст. 2 Ф3 №126). Конституционное право каждого человека на тайну телефонных переговоров интерпретируется как гарантированное государством право на тайну телефонных переговоров, передаваемых по сетям электросвязи.

9 «Сеть почтовой связи - совокупность объектов почтовой связи и почтовых маршрутов» (ст. 2 Ф3 № 176).

10 «Государственная автоматизированная информационная система «ЭРА - ГЛОНАСС» - федеральная госу- 
Такие гарантии, по нашему мнению, в свою очередь, выступают как дополнительные основные права ${ }^{11}$ и являются конкретизацией ч. 2 ст. 23 Конституции Российской Федерации, предусматривающей право на тайну телефонных переговоров и иных сообщений.

При этом самостоятельность и ценность конституционного права каждого на тайну телефонных переговоров как гарантии общих основных прав имеет особую значимость. На это указывает подход законодателя, возведшего названную гарантию в конституционный ранг, которая, наряду с другими, играет важную роль в правовом статусе человека и гражданина Российской Федерации, взаимоотношениях гражданина и государства на современном этапе развития российского общества.

Следует сказать и о том, что на защите реализации права каждого на тайну телефонных переговоров стоит более широкая категория основных прав. В частности, нарушение тайны индивидуальной коммуникации ${ }^{12}$ следует рассматривать как противоправное вторжение в право на неприкосновенность частной жизни, о чем говорит ч.1 ст. 23 Конституции Российской Федерации. Такое нарушение одновременно может быть связано с нарушением запрета на доступ к информации о частной жизни лица без его согласия, установленного ч. 1 ст. 24 Конституции Российской Федерации.

дарственная территориальная распределительная автоматизированная информационная система экстренного реагирования при авариях, обеспечивающая оперативное получение формируемой в некорректируемом виде на основе использования сигналов глобальной навигационной спутниковой системы Российской Федерации информации о дорожно-транспортных и об иных происшествиях на автомобильных дорогах в Российской Федерации, обработку этой информации, ее хранение и передачу в экстренные оперативные службы, а также доступ к этой информации государственных органов, органов местного самоуправления, должностных лиц, юридических лиц, физических лиц» (п. 1. ст. 2 Федерального закона № 395-Ф3 «О Государственной автоматизированной информационной системе «ЭРА - ГЛОНАСС»). См.: О навигационной деятельности: Федеральный закон Российской Федерации от 14 февраля 2009 г. № 22-Ф3.

11 Подробнее о соотношении основных прав см.: Права человека: Кол. авт.; Т.А. Василъева, В.А. Карташкин, И.А. Ледях / отв. ред. Е.А.Лукашева. - М., 1999. - С. 142-151.

12 Коммуникация - специфический обмен информацией, в результате которого происходит процесс (коммуникативный процесс) передачи информации интеллектуального и эмоционального содержания от отправителя к получателю. См.: Володин, Т.В. Деловое общение и основы теории коммуникации / Т.В. Володин, О.К. Карпухина. - СПб, 2002. - С. 7.
Подчеркнем, что обеспечение защиты реализации права на тайну телефонных переговоров законодатель реализует как бы заблаговременно: при построении и эксплуатации сетей связи и сооружений. В ст. 7 Федерального закона «О связи» говорится: «Операторы связи и застройщики при строительстве и реконструкции зданий, строений, сооружений (в том числе сооружений связи), а также при построении сетей связи должны учитывать необходимость защиты средств связи от несанкционированного доступа к ним ${ }^{13}$. Операторы связи при эксплуатации сетей связи и сооружений связи обязаны обеспечивать защиту средств связи и сооружений связи от несанкционированного доступа к ним» ${ }^{14}$.

На защите реализации права граждан на тайну телефонных переговоров стоит и отраслевое законодательство ${ }^{15}$. В частности, уголовное ${ }^{16}$, административное. Статья 138 УК РФ предусматривает уголовную ответственность за нарушение тайны телефонных переговоров. Косвенно она охраняется и ст. 138.1 УК РФ, предусматривающей уголовную ответственность за незаконный оборот специальных технических средств, предназначенных для негласного получения информации. В тех случаях, когда имеет место нарушение неприкосновенности частной жизни (незаконное собирание или распространение сведений о частной жизни лица, составляющих его личную или семейную тайну, без согласия, либо распространение этих сведений в

13 В редакции Федерального закона от 09.02.2007 № 14-ФЗ.

14 Статья 7 Федерального закона Российской Федерации от 7 июля 2003 года № $126-Ф 3$ «О связи».

15 «К сожалению, право на тайну личной жизни не отражено в действующем гражданском законе. С теоретической же точки зрения право на тайну личной жизни представляет собой абсолютное право, в силу которого управомоченное лицо вправе требовать сохранения в тайне информации, полученной с его согласия либо в силу закона без его согласия, а также прекращения ее распространения. Предъявление управомоченным лицом требований в защиту этого права не препятствует возможности истребовать возмещения ущерба, возникшего в результате нарушения права на тайну личной жизни». См.: Шерстобитов, А.Е. Охрана индивидуальной свободы и личной жизни граждан в гражданском праве / А.Е. Шерстобитов // Гражданское право: в 4-х т. Т. II: Вещное право. Наследственное право. Исключительные права. Личные неимущественные права. - М., 2008. - С. 433-434.

16 См.: Стародубцева, И.А. Коллизии между Конституцией и Уголовным кодексом РФ в сфере конституционных прав и свобод человека и гражданина / И.А. Стародубцева, С.А. Коняев // Конституционное и муниципальное право. - 2011. № 9. - С. 71-73. 
публичном выступлении, публично демонстрирующемся произведении или средствах массовой информации), наступает уголовная ответственность по ст. 137 УК РФ. Статья 13.11 Кодекса Российской Федерации об административных правонарушениях (сформулирована с определенной конкретизацией, указанием на персональные данные) предусматривает ответственность за нарушение установленного законом порядка сбора, хранения, использования или распространения информации о гражданах (персональных данных) ${ }^{17}$.

В части 2 ст. 23 действующей Конституции Российской Федерации, наряду с правом каждого на тайну телефонных переговоров, говорится и $o$ «иных сообщениях» (иные сообщения фигурируют в нормах отдельных федеральных законов) ${ }^{18}$. В связи с чем возникает вопрос, что понимает законодатель под иными сообщениями ${ }^{19}$. Поставленный вопрос в реализации конституционного права на тайну телефонных переговоров не является единственным.

Как мы уже указывали, Всеобщая декларация прав человека, Конвенция о защите прав человека и основных свобод, Международный пакт о гражданских и политических правах, Конвенция ООН о трудящихся-мигрантах, Конвенция ООН о правах ребенка говорят о тайне (уважении) «корреспонденции». Отметим, что в решениях Европейского Суда по правам человека (по конкретным делам) также фигурирует термин «корреспонденция», который наряду с телефонными переговорами включается в понятие «частная жизнь», закрепленного в ст. 8 Конвенции о защите прав человека и основных свобод ${ }^{20}$. Более того термин «кор-

17 См.: О персональных данных: Федеральный закон Российской Федерации от 27 июля 2006 г. № 152-Ф3.

18 Федеральный закон Российской Федерации от 17 июля 1999 года № 176 - Ф3 «О почтовой связи» тайну связи определяет как тайну переписки, почтовых, телеграфных и иных сообщений, входящих в сферу деятельности операторов почтовой связи, не подлежащую разглашению без согласия пользователя услуг почтовой связи.

19 Этимологически под сообщением понимается «то, что сообщается, известие, информация» (см.: Ожегов, С.И. Толковый словарь русского языка / С.И. Ожегов, Н. Ю. Шведова. М., 1999. - С.747), а под термином сообщить - «уведомить, известить, довести до чьего-нибудь сведения» (там же).

20 Решение Европейского Суда по правам человека по делу Класс от 6 сентября 1978 г. цитируется по: Гомъен, Д.Л. Европейская конвенция о правах человека и Европейская социальная хартия: право и практика / Д. Гомъен, Д. Харрис, Л. Зваак. - М., 1998. - С.270, 278. респонденция» рассматривается Европейским Судом по правам человека как понятие, охватывающее все виды переговоров (сообщений) и отправлений, передаваемых учреждениями связи, в том числе телефонные переговоры. В русском же языке под корреспонденцией понимается «обмен письмами, переписка; письма, почтово-телеграфные отправления» ${ }^{21}$. В отдельных случаях под корреспонденцией имеются в виду те сообщения (сведения, информация), которые предъявлены через определенные материальные носители ${ }^{22}$. В конституционном праве, правоприменительной и судебной практике к таким носителям относятся переписка, почтовые отправления, телеграммы, сообщения и корреспонденция, которые рассматриваются как равнозначные.

Конституционный Суд Российской Федерации в одном из своих определений указал, что «информацией, составляющей охраняемую Конституцией Российской Федерации и действующими на территории Российской Федерации законами тайну телефонных переговоров, считаются любые сведения, передаваемые, сохраняемые и устанавливаемые с помощью телефонной аппаратуры, включая данные о входящих и исходящих сигналах соединения телефонных аппаратов конкретных пользователей связи» ${ }^{23}$.

Телефонные переговоры осуществляются по двум типам линий связи: радиолиниям (в атмосфере) и кабельно-проводным (направляющим) ${ }^{24}$. К числу аудиальных (воспринимаемых слухом) систем связи относится наиболее массовый вид проводные телефонные, а также телеграфные, факсимильные. Что касается иных переговоров, то они могут осуществляться с использованием систем компьютерной телефонии. Этот класс систем

21 Булыко, А.Н. Большой словарь иностранных слов / А.Н. Булыко. - М., 2011. - С. 296; Ожегов, С.И. Толковый словарь русского языка / С.И. Ожегов, Н. Ю. Шведова. - М., 1999. - C. 298.

22 Современный словарь иностранных слов. - М., 1994. C.313.

23 См.: Об отказе в принятии к рассмотрению запроса Советского районного суда города Липецка «О проверке конституционности части четвертой статьи 32 Федерального закона от 16 февраля 1995 г. «О связи»: Определение Конституционного Суда Российской Федерации от 02.10.2003 № 345-О // Интернет-ресурс.

24 По исполнению направляющие линии связи бывают кабельные, воздушные и волоконно-оптические. См.: Ярочкин, В.И. Информационная безопасность / В.И. Ярочкин. M., 2006. - C.241. 
основан на интеграции возможностей телефонных станций и современного компьютерного оборудования со специализированным программным обеспечением. Наиболее распространены системы: голосовой почты, позволяющей организовать необходимое количество виртуальных автоответчиков с возможностью обработки входящих голосовых сообщений (на основе названной системы решается широкий спектр задач по обработке входящей и исходящей голосовой информации); конференц-связи, предназначенной для работы внутренних и внешних абонентов АТС с широкими возможностями контроля и управления; тарификации, предназначенной для учета количества и времени переговоров через офисную или учрежденческую ATC, с выдачей отчетов и анализом расходов; записи телефонных переговоров, позволяющей записывать, осуществлять поиск и воспроизводить сделанные записи.

В отдельных министерствах, службах, агентствах осуществляется передача сообщений по сетям документальной электросвязи (СДЭС), используемых для предоставления услуг передачи данных и телематических служб (факс, телекс, телефакс), включая сеть Интернет.

Вместе с тем, в российской и зарубежной юридической литературе существует и более широкое понятие «коммуникация», а в российском законодательстве применяется, как отмечалось, термин «связь» (Федеральный закон «О связи», Федеральный закон «0 почтовой связи»).

Названные понятия определенным образом связаны. В частности, категория «коммуникация» охватывает понятие «связь» и, соответственно, - понятие «сообщения», существующие в конституционном праве России, а также понятие «корреспонденция», закрепленное в ч.1 ст. 8 Конвенции о защите прав человека и основных свобод. При этом ни категория «коммуникация», ни понятие «связь» не сводятся только к понятиям «корреспонденция» или «сообщения». Наряду с корреспонденцией (сообщениями как материализованными носителями информации), категория «коммуникация» ${ }^{25}$ («связь», «электросвязь») охватывает, прежде всего, понятие «сети связи», под которыми понимается технологическая система, включающая в себя средства и линии связи и предназначенная для электросвязи или почтовой связи (п. 24 ст. 2 Федерального

25 «Коммуникация - линия связи, например, телеграфная, телефонная, радио; обмен мыслями, передача информации при помощи языка». См.: Булыко, А.Н. Указ. раб. - С. 281. закона «0 связи»). Линии связи включают линии передачи, физические цепи и линейно-кабельные сооружения связи (п.7 ст. 2 Федерального закона «0 связи»). Средства связи представляют собой технические и программные средства, используемые для формирования, приема, обработки, хранения, передачи, доставки сообщений электросвязи или почтовых отправлений, а также иные технические и программные средства, используемые при оказании услуг связи или обеспечении функционирования сетей связи, включая технические системы и устройства с измерительными функциями (ст.2 Федерального закона «0 связи»)26.

Что касается электросвязи, то под ней понимаются любые излучения, передача или прием знаков, сигналов, голосовой информации, письменного текста, изображений, звуков или сообщений любого рода по радиосистеме, проводной, оптической и другим электромагнитным системам» (п. 35 ст. 2 Федерального закона «0 связи»).

Анализируя практику несанкционированного получения информации, скажем, что оно осуществляется за счет приема электромагнитных сигналов радиодиапазона. Источниками излучения радиоволн различных диапазонов являются: средства радиосвязи, предназначенные для обеспечения мобильной и стационарной систем, в том числе спутников, радиорелейных и других; средства сотовой радиосвязи; средства пейджинговой связи; средства оперативной служебной радиосвязи; сигналы радиотелефонных удлинителей; сигналы радиомикрофонов; сигналы технических средств и систем (радиолокационные, радионавигационные системы, сигналы средств электронно-вычислительной техники и пр.); другие системы открытого излучения радиосигналов связного или технологического характера (например, средств обеспечения полетов самолетов, средств спасения на водах и пр.) ${ }^{27}$.

В США под электронным сообщением понимается «...любая передача знаков, сигналов, письменных сообщений, звуков, данных или информации любого характера, передаваемой целиком или частично по проводам, радиоэлектронными, фотоэлектронным или оптическим системам, которые используются при общении между штатами и между городами, за исключением:

a) любой передачи устной информации по проводной связи;

\footnotetext{
26 В редакции Федерального закона от 07.11.2011 № 303-Ф3.

27 Ярочкин, В.И. Указ. раб. - С. 249.
} 
б) любой информации, передаваемой на пейджер в тоновом режиме;

в) любой информации, передаваемой с устройства слежения;

г) информации о передаче электронных счетов, хранимых финансовым учреждением в коммуникационной системе» ${ }^{28}$.

Приведенные понятия на этапе принятия Конституции Российской Федерации не нашли в ней отражения по ряду объективных обстоятельств. С одной стороны, это сделать было невозможно (отсутствовали сами технологии передачи информации), а с другой - нецелесообразно, по той причине, что в ней должны отражаться стратегические (долгосрочные) положения. Конституции Российской Федерации и без того объемный, подробный документ, в отличие от тех, которые имеются в некоторых странах Европы.

Результатом современного научно-технического прогресса является повсеместное внедрение современных компьютерных, цифровых технологий, плотной телефонизации, интенсивное развитие сотовой радиотелефонной связи ${ }^{29}$, которые создают техногенный компонент в отношениях государства и личности, делают указанные отношения объективно открытыми ${ }^{30}$. В 2009 году сотовой связью, к примеру, пользовалось 3,3 млрд. абонентов, притом, что население Земли насчитывало около 6,6 млрд. человек ${ }^{31}$. И чем сильнее развиваются наукоемкие

2818 U.S.C., параграфа 2510 (1). Следует иметь в виду, что большинство сообщений, передаваемых через Интернет (включая электронную почту), являются информацией в электронном виде.

29 В соответствии с Декларацией об использовании научнотехнического прогресса в интересах мира и на благо человечества (провозглашена резолюцией 3384 (XXX) Генеральной Ассамблеи от 10 ноября 1975 г.) «все государства принимают соответствующие меры с тем, чтобы предотвратить использование достижений науки и техники, в частности, государственными органами, для ограничения или вмешательства в осуществление прав человека и основных свобод, провозглашенных во Всеобщей декларации прав человека, Международных пактах о правах человека и других соответствующих международных документах». См.: Международные акты о правах человека: сб. документов. - М., 1999. - С. 338.

30 См.: Калашников, С.В. Политические гарантии обеспечения конституционных прав, свобод и законных интересов личности в условиях формирования гражданского общества в Российской Федерации / С.В. Калашников // Российская юстиция. - 2012. — № 12. - С. 2-5.

31 См.: Козинкин, В.А. Использование в расследовании преступлений информации, обнаруживаемой в средствах сотовых систем подвижной связи / В.А. Козинкин: автореф. дис.... технологии в сфере коммуникаций, тем более прозрачными становятся границы личной жизни человека. Одним из главных средств, «ломающих» эти границы, стали современные коммуникационные системы и, прежде всего, связь.

Достижения научно-технического прогресса кардинальным образом изменили систему коммуникаций, составляющей которой выступают современные сети передачи информации, в том числе и в глобальном масштабе. Это, естественно, не могло не сказаться на реализации права на тайну телефонных переговоров и иных сообщений.

В настоящее время уместно говорить о сформированном «киберпространстве», которое делает незыблемость границ частной, личной и семейной жизни весьма призрачным. Чтобы обеспечить надлежащую и всестороннюю защиту права на тайну телефонных переговоров, законодатель использовал терминологию (иные сообщения), позволяющую толковать ее предельно широко. Такой подход, по нашему мнению, заключался в том, что законодательное расширение предмета конституционного регулирования допустимо, если такое расширение усиливает гарантии частной жизни лица.

А. Бэкси в своей книге «Будущее прав человека», анализируя последствия возникновения научно-технических конструкций власти, пишет, что в эпоху цифрового капитализма изменилось само понятие человеческого. Человек представляется киборгом, помещенным в сети информации, полностью принадлежащим корпорации. Различные проекты человеческого генома и современные оправдания технологий клонирования человека как спасающие человека от страданий являют собой знаменательный, если не окончательный, вызов, по мнению А. Бэкси, полувековой принадлежности к веку прав человека (носитель прав человека переделывается в киборга либо в информационное генетическое хранилище). В этом от-

канд. юрид. наук. - М., 2009. - С. 3. За последние пять лет число россиян, имеющих мобильный телефон, возросло с $75 \%$ до $90 \%$, в том числе с $7 \%$ до $15 \%$ - пользующихся двумя и с $3 \%$ до $6 \%$ - тремя мобильными телефонами. Среди тех, кто не пользуется мобильной связью (в целом 10\%), чаще встречаются граждане старше 55 лет и с невысокими доходами (по $21 \%)$, с образованием ниже среднего (15\%) и проживающие на селе (13\%). Нет мобильного телефона всего у $2 \%$ россиян в возрасте $25-39$ лет, у $4 \%$ жителей Москвы и обеспеченных россиян, у 5\% граждан с высшим образованием. Согласно данным, опубликованным Международным союзом электросвязи, в мире уже шесть миллиардов человек имеют мобильные телефоны. Треть из них - это жители Китая и Индии. 
ношении права человека оказываются еще более чувствительными к режимам научно-технической власти, нежели к государственному насилию и другим формам насилия, утверждающим миропорядок, основанный на языке оружия и денег» ${ }^{32}$.

Обратим внимание еще на одно обстоятельство, имеющее существенное значение в реализации права на тайну телефонных переговоров. Международно-правовые акты, равно как и Конституция Российской Федерации, не рассматривают право на тайну телефонных переговоров как право абсолютное. Это право согласно международноправовым документам может быть ограничено при законодательно определенных условиях. Однако такие условия в указанных актах не определяются. Они получили более четкую регламентацию в праве Европейского сообщества, закрепляющего право на уважение корреспонденции.

В праве Европейского сообщества право на уважение корреспонденции получает развернутое позитивное определение ${ }^{33}$, с указанием случаев, когда его нарушение допускается и в каких целях. Тем самым Конвенция о защите прав человека и основных свобод преодолевает неопределенность ст.12 Всеобщей декларации прав человека, которая защищает от «произвольного вмешательства». Это вмешательство, по нашему мнению, следует рассматривать как вторжение в право личной свободы третьих лиц, осуществляемое вопреки закону и без ясно сформулированных целей. Конвенция определяет содержание этого права гораздо более четко. Часть 2 ст. 8 Конвенции о защите прав человека и основных свобод гласит: «Не допускается вмешательство государственных органов в осуществление этого права, за исключением случаев, когда это предусмотрено законом и необходимо в демократическом обществе в интересах государственной безопасности, общественного порядка или экономического благосостояния страны, для поддержания порядка и предотвращения преступлений, в целях предотвращения беспорядков или преступлений, охраны здоровья или защиты нравственности или защиты прав и свобод других лиц»

Итак, согласно Всеобщей декларации прав человека, Конвенции о защите прав человека и основных свобод, Международному пакту о гражданских и политических правах, все граждане имеют право на конфиденциальность корреспонденции. Однако данное право может быть ограничено «в соответствии с законом», если это «необходимо в демократическом обществе».

Подводя итог изложенному в данном парагра$ф е$, отметим, что Конституция Российской Федерации, в ч. 2 ст. 23, указывает и на процедуру ограничения тайны телефонных переговоров, допуская это только на основании судебного решения. Федеральное законодательство конкретизирует конституционное положение, указывая, что оно осуществляется при наличии достаточных оснований полагать, что телефонные и иные переговоры подозреваемого, обвиняемого и других лиц могут содержать сведения, имеющие значение для уголовного дела. Их контроль и запись допускаются при производстве по уголовным делам о преступлениях средней тяжести, тяжких и особо тяжких преступлениях на основании судебного решения, принимаемого в порядке ст. 165 УПК РФ (ч. 1 ст. 186 УПК РФ). При этом следователь с согласия руководителя следственного органа, а дознаватель с согласия прокурора возбуждает перед судом ходатайство о производстве следственного действия, о чем выносится постановление ${ }^{34}$.

\section{Библиография:}

1. Баглай М.В. Конституционное право Российской Федерации.-М., 1997.

2. Булыко А.Н. Большой словарь иностранных слов.-М., 2011.

3. Калашников С.В. Политические гарантии обеспечения конституцион-ных прав, свобод и законных интересов личности в условиях формирования гражданского общества в Российской Федерации // Российская юстиция.-2012.-№ 12.

\footnotetext{
32 Цитируется по: Умнова, И.А. Современные концепции прав человека в международно-правовом и конституционном измерениях / И.А. Умнова // Омбудсмен. - 2012. — № 2 // КонсультантПлюс. См. также: Малевич, Ю.И. Права человека в глобальном мире / Ю.И. Малевич. - М., 2004.

33 См.: Кудрявцев, М. Концепция прав человека в Хартии европейского союза об основных правах / М. Кудрявцев // Международное правосудие. - 2013. - № 2. - С. 40-54.
}

\begin{abstract}
34 Прослушивание телефонных переговоров (п.10 ч. 1 ст. 6. Федерального закона Российской Федерации «Об оперативно-розыскной деятельности») в данном случае не рассматривается. За 10 месяцев 2013 года по инициативе прокуроров было предотвращено 200 необоснованных следственных действий, связанных с контролем телефонных и иных переговоров. См.: Чайка, Ю. Законный вопрос // Ю. Чайка // Российская газ. $-2014 .-10$ янв.
\end{abstract}


4. Кудрявцев М. Концепция прав человека в Хартии европейского союза об основных правах // Международное правосудие.-2013.-№ 2.

5. Куракин А.В., Костенников М.В. Административно-правовое регули-рование информационной безопасности в системе государственной граждан-ской службы. - Домодедово, 2012.

6. Куракин А.В., Костенников М.В. Актуальные проблемы администра-тивного права. - М., 2013.

7. Ярочкин В.И. Информационная безопасность.-М., 2006.

8. Гуляихин В.Н. Структурно-функциональные особенности различных состояний правосознания человека // NB: Вопросы права и политики.-2012.-2.-C. 90-116. URL: http://www.e notabene.ru/lr/ article_153.html

9. Несмелов П.В. К вопросу о конфиденциальной информации в административном праве // Полицейская деятельность.-2012.-4.-С. 60-65.

10. Бабин Б.В. Право на сопротивление как глобальное право. // NB: Вопросы права и политики.-2013.5.-C. 181-200. DOI: 10.7256/2305-9699.2013.5.817. URL: http://www.e-notabene.ru/lr/article_817.html

11. Вахрамеев Р.Г. Механизм правового регулирования конституционного права на информацию // NB: Вопросы права и политики.-2013.-12.-C. 23-34. DOI: 10.7256/2305-9699.2013.12.9854. URL: http:// www.e-notabene.ru/lr/article_9854.html.

12. Владимирова Т.В.. Информационная безопасность: социологическая перспектива понятия. // Национальная безопасность / nota bene.-2013.-№ 4.-C. 597-604. DOI: .10.7256/2073-8560.2013.4.747

\section{References:}

1. Baglai M.V. Konstitutsionnoe pravo Rossiiskoi Federatsii.-M., 1997.

2. Bulyko A.N. Bol'shoi slovar' inostrannykh slov.-M., 2011.

3. Kalashnikov S.V. Politicheskie garantii obespecheniya konstitutsion-nykh prav, svobod i zakonnykh interesov lichnosti v usloviyakh formirovaniya grazhdanskogo obshchestva v Rossiiskoi Federatsii // Rossiiskaya yustitsiya.-2012.-№ 12.

4. Kudryavtsev M. Kontseptsiya prav cheloveka v Khartii evropeiskogo soyuza ob osnovnykh pravakh // Mezhdunarodnoe pravosudie.-2013.-№ 2.

5. Kurakin A.V., Kostennikov M.V. Administrativno-pravovoe reguli-rovanie informatsionnoi bezopasnosti v sisteme gosudarstvennoi grazhdan-skoi sluzhby. - Domodedovo, 2012.

6. Kurakin A.V., Kostennikov M.V. Aktual'nye problemy administra-tivnogo prava. - M., 2013.

7. Yarochkin V.I. Informatsionnaya bezopasnost'.-M., 2006.

8. Gulyaikhin V.N. Strukturno-funktsional'nye osobennosti razlichnykh sostoyanii pravosoznaniya cheloveka // NB: Voprosy prava i politiki.-2012.-2.-C. 90-116. URL: http://www.e notabene.ru/lr/article_153.html

9. Nesmelov P.V. K voprosu o konfidentsial'noi informatsii $\mathrm{v}$ administrativnom prave // Politseiskaya deyatel'nost'.-2012.-4.-C. 60-65.

10. Babin B.V. Pravo na soprotivlenie kak global'noe pravo. // NB: Voprosy prava i politiki.-2013.-5.-C. 181-200. DOI: 10.7256/2305-9699.2013.5.817. URL: http://www.e-notabene.ru/lr/article_817.html

11. Vakhrameev R.G. Mekhanizm pravovogo regulirovaniya konstitutsionnogo prava na informatsiyu // NB: Voprosy prava i politiki.-2013.-12.-C. 23-34. DOI: 10.7256/2305-9699.2013.12.9854. URL: http://www.e-notabene.ru/lr/article_9854.html.

12. Vladimirova T.V.. Informatsionnaya bezopasnost': sotsiologicheskaya perspektiva ponyatiya. // Natsional'naya bezopasnost' / nota bene.-2013.-№ 4.-C. 597-604. DOI: .10.7256/2073-8560.2013.4.747 